\title{
Focal mechanisms and the stress field in the aftershock area of the 2018 Hokkaido Eastern Iburi earthquake $\left(M_{\mathrm{JMA}}=6.7\right)$
}

Yuki Susukida ${ }^{1,12}$, Kei Katsumata ${ }^{1 *} \mathbb{D}$, Masayoshi Ichiyanagi ${ }^{1}$, Mako Ohzono ${ }^{1}$, Hiroshi Aoyama', Ryo Tanaka', Masamitsu Takada' , Teruhiro Yamaguchi ${ }^{1}$, Kazumi Okada ${ }^{1}$, Hiroaki Takahashi', Shin'ichi Sakai ${ }^{2}$, Satoshi Matsumoto ${ }^{3}$, Tomomi Okada $^{4}$, Toru Matsuzawa ${ }^{4}$, Hiroki Miyamachi ${ }^{5}$, Shuichiro Hirano ${ }^{6}$, Yoshiko Yamanaka ${ }^{7}$, Shinichiro Horikawa ${ }^{7}$, Masahiro Kosuga $^{8}$, Hiroshi Katao ${ }^{9}$, Yoshihisa lio ${ }^{9}$, Airi Nagaoka ${ }^{9}$, Noriko Tsumura ${ }^{10}$, Tomotake Ueno ${ }^{11}$ and The Group for the Aftershock Observations of the 2018 Hokkaido Eastern Iburi Earthquake

\begin{abstract}
The tectonic stress field was investigated in and around the aftershock area of the Hokkaido Eastern Iburi earthquake $\left(M_{\mathrm{JMA}}=6.7\right)$ occurred on 6 September 2018. We deployed 26 temporary seismic stations in the aftershock area for approximately 2 months and located 1785 aftershocks precisely. Among these aftershocks, 894 focal mechanism solutions were determined using the first-motion polarity of $\mathrm{P}$ wave from the temporary observation and the permanent seismic networks of Hokkaido University, Japan Meteorological Agency (JMA), and High Sensitivity Seismograph Network Japan (Hi-net). We found that (1) the reverse faulting and the strike-slip faulting are dominant in the aftershock area, (2) the average trend of $\mathrm{P}$ - and T-axes is $78^{\circ} \pm 33^{\circ}$ and $352^{\circ} \pm 51^{\circ}$, respectively, and (3) the average plunge of $\mathrm{P}$ - and T-axes is $25^{\circ} \pm 16^{\circ}$ and $44^{\circ} \pm 20^{\circ}$, respectively: the P-axis is close to be horizontal and the T-axis is more vertical than the average of the P-axes. We applied a stress inversion method to the focal mechanism solutions to estimate a stress field in the aftershock area. As a result, we found that the reverse fault type stress field is dominant in the aftershock area. An axis of the maximum principal stress $\left(\sigma_{1}\right)$ has the trend of $72^{\circ} \pm 7^{\circ}$ and the dipping eastward of $19^{\circ} \pm 4^{\circ}$ and an axis of the intermediate principal stress $\left(\sigma_{2}\right)$ has the trend of $131^{\circ} \pm 73^{\circ}$ and the dipping southward of $10^{\circ} \pm 9^{\circ}$, indicating that both of $\sigma_{1}$ - and $\sigma_{2}$-axes are close to be horizontal. An axis of the minimum principal stress $\left(\sigma_{3}\right)$ has the dipping westward of $67^{\circ} \pm 6^{\circ}$ that is close to be vertical. The results strongly suggest that the reverse-fault-type stress field is predominant as an average over the aftershock area which is in the western boundary of the Hidaka Collision Zone. The average of the stress ratio $R=\left(\sigma_{1}-\sigma_{2}\right) /\left(\sigma_{1}-\sigma_{3}\right)$ is $0.61 \pm 0.13$ in the whole aftershock area. Although not statistically significant, we suggest that $R$ decreases systematically as the depth is getting deep, which is modeled by a quadratic polynomial of depth.
\end{abstract}

Keywords: The Hokkaido Eastern Iburi earthquake, Reverse fault, Aftershock distribution, Focal mechanism solution, Temporary seismic network, Stress inversion

\footnotetext{
*Correspondence: kkatsu@sci.hokudai.ac.jp

${ }^{1}$ Faculty of Science, Institute of Seismology and Volcanology, Hokkaido

University, Sapporo, Japan

Full list of author information is available at the end of the article
}

\begin{abstract}
Introduction
The tectonic regime is complicated in Hokkaido corner, Japan subduction zone (Fig. 1). The Pacific (PA) plate is moving toward $\mathrm{N} 63^{\circ} \mathrm{W}$ with a speed of $8.2 \mathrm{~cm} /$ year (DeMets et al 1994) and subducting below the North American (NA) plate or the Okhotsk (OK) plate on
\end{abstract}




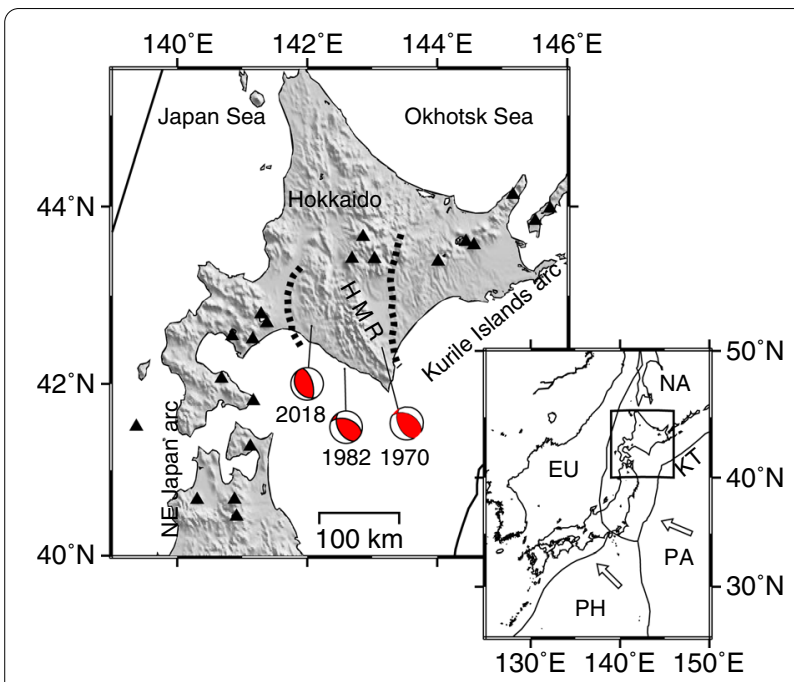

Fig. 1 Map showing the Hokkaido corner. Inset shows the plate boundaries (Bird 2003) and the study area in rectangle. The region in and around the Hidaka Mountain Range (HMR) is the Hidaka Collision Zone (HCZ). Two broken lines show the eastern and the western boundaries of the HCZ. Closed triangles indicate active volcanoes. A red beach ball labeled as 2018 is the centroid moment tensor (CMT) solution of the 2018 Hokkaido Eastern Iburi earthquake (M6.7) (JMA 2018a). A red beach ball labeled as 1982 is the focal mechanism solution of the 1982 Urakawa-oki earthquake (M7.1) by using the first motion polarity of $\mathrm{P}$ wave (Moriya et al 1983). A red beach ball labeled as 1970 is the focal mechanism solution of the 1970 Hidaka earthquake (M6.7) by using the first motion polarity of P wave (Kita et al 2012). PA: Pacific plate, PH: Philippine Sea plate, EU: Eurasian plate, NA: North American plate, and KT: Kurile Trench

which the Hokkaido Island is located (Takahashi et al 1999; Katsumata et al 2002, 2003). The upper surface of the PA plate strongly coupled with the overriding plate in and around the Kurile Trench (Hashimoto et al 2009) and shallow great earthquakes have been caused repeatedly. This subduction process possibly produces a compressional stress field with the direction of NW-SE in the inland area of Hokkaido Island. Moreover, a collision process is in progress. The Kurile Islands arc and the NE Japan arc are colliding in and around the Hidaka Mountain Range (HMR) (Kimura 1981, 1986, 1996; Seno 1985; Moriya 1986; Arita et al 2001). This is called the Hidaka Collision Zone (HCZ). The speed of the collision is estimated to be $6-11 \mathrm{~mm} /$ year relative to the NA plate based on the horizontal slip direction from shallow-thrust earthquakes (DeMets 1992). This collision process possibly produces a compressional stress field in the $\mathrm{HCZ}$ with the direction of NE-SW. Additionally, the upper crust and the lower crust beneath the $\mathrm{HCZ}$ are not a simple layered structure (Ozel et al 1996; Moriya et al 1998; Iwasaki et al 2004; Shiina et al 2018).

Some tectonic models have been proposed for the HCZ. The crust of the Kurile Islands arc has been torn in the east of the HMR due to the collision and divided into the upper part and the lower part (Ito et al 1999; Murai et al 2003). The upper part is riding over the NE Japan arc in the west of the HMR. The lower part is in contact with the upper boundary of the PA plate, dragged into the upper mantle, and scraped (Moriya 1999; Tsumura et al 1999). Kita et al (2012) insisted that the mantle material might be rising directly from the uppermost mantle of the Kurile Islands arc. These complicated structures may cause a complicated stress field and produce earthquakes with a variety of the focal mechanisms.

Recently, two large earthquakes occurred in the crust of the HCZ: the 1970 Hidaka earthquake $\left(M_{\mathrm{JMA}}=6.7\right)$ (Motoya and Kitagamae 1971; Moriya 1972) and the 1982 Urakawa-oki earthquake $\left(M_{\mathrm{JMA}}=7.1\right)$ (Moriya et al 1983). The focal mechanism solutions of the two earthquakes are similar: the reverse faulting with the P-axis in the direction of NE-SW (Kita et al 2012). Both earthquakes were in the central part of the $\mathrm{HCZ}$ and thus the compressional stress filed in the direction of NE-SW is dominant at least in the central part of the HCZ. This idea was supported by Terakawa and Matsu'ura (2010), founding that the reverse-fault-type stress field is dominant in and around the $\mathrm{HCZ}$ and the maximum principal stress $\left(\sigma_{1}\right)$ is oriented to nearly NE-SW. Kita et al (2012) applied a stress inversion analysis to small earthquakes in the central part of the $\mathrm{HCZ}$ and they found that the $\sigma_{1}$ axis is oriented to nearly NE-SW.

In the western boundary of the HCZ, a large earthquake occurred on 6 September 2018: The Hokkaido Eastern Iburi earthquake $\left(M_{\mathrm{IMA}}=6.7\right)$. Although the focal mechanism of the main shock was estimated as a strike-slip faulting by using the first motion polarities of P wave (JMA 2018b; NIED 2018b; Katsumata et al 2019), the centroid moment tensor (CMT) solution shows the reverse faulting with the $\mathrm{P}$-axis in the direction of NESW (JMA 2018a; NIED 2018a). The mismatch between the focal mechanism solution and the CMT solution has been explained by a model that a large reverse faulting occurred immediately after an initial rupture of a small strike-slip faulting (Katsumata et al 2019). The CMT solution of the 2018 Hokkaido Eastern Iburi earthquake is similar to the focal mechanisms of the 1970 Hidaka earthquake and the 1982 Urakawa-oki earthquake, clearly indicating that the compressional stress field due to the collision extends to the western boundary of the HCZ (Terakawa and Matsu'ura 2010; Hua et al 2019).

The main shock of the 2018 Hokkaido Eastern Iburi earthquake was followed by many aftershocks. We deployed temporary seismic stations densely in the aftershock area to determine the hypocenters and the focal mechanisms accurately. The purpose of this study was to determine the focal mechanisms of the 
aftershocks, to apply a stress inversion method to the focal mechanisms, and to make some discussions on the detailed spatial pattern of the stress field in the aftershock area.

\section{Data}

To obtain aftershocks data in detail, we deployed 26 temporary seismic stations in the focal area immediately after the main shock and observed aftershocks for approximately 2 months (Fig. 2; Additional file 1). The temporary observation was conducted by the Group for the Aftershock Observations of the 2018 Hokkaido Eastern Iburi Earthquake, which consists of Hokkaido University, Hirosaki University, Tohoku University, Chiba University, the University of Tokyo, Nagoya University, Kyoto University, Kyushu University, Kagoshima University, and the National Research Institute for Earth Science and Disaster Resilience (NIED). The temporary seismographic stations consisted of 4 telemetered systems and 22 portable offline systems. We also used 183 permanent online seismographic stations maintained by Hokkaido University, JMA, and NIED. Waveform data observed during the period from 6 September 2018 to 31 October 2018 were examined carefully by visual inspection, and the arrival times of $\mathrm{P}$ and $\mathrm{S}$ waves and the first motion polarities of $\mathrm{P}$ wave were read manually by a welltrained person.

\section{Methods}

We determined hypocenters of earthquakes with the maximum likelihood estimation algorithm of Hirata and Matsu'ura (1987) using the 1D velocity structure of P wave based on Kasahara et al (1994) (Fig. 2), which is the same as that used for the hypocenter calculation at the Hokkaido University. The $S$ wave velocity was obtained by the relationship $V_{P} / V_{S}=\sqrt{3}$, where $V_{\mathrm{P}}$ and $V_{\mathrm{S}}$ are the $P$ and $S$ wave velocities, respectively. We located 1785 earthquakes in the study area $\left(42.5-42.9^{\circ} \mathrm{N}, 141.8-142.2^{\circ}\right.$ E), observed from 2018-09-06 03:00 to 2018-10-31 23:59 with depths shallower than $50 \mathrm{~km}$ and the magnitude ranging from 0.2 to 5.9 (Fig. 3). The maximum amplitude on the vertical component was measured and the magnitude was calculated by using an empirical equation (Watanabe 1971).

We determined focal mechanism solutions of earthquakes by using a grid-search technique developed by Hardebeck and Shearer (2002). We used two 1D velocity structures to take the uncertainty of ray paths, especially take-off angle from the hypocenter, into account (Fig. 2). The first one is a hybrid of two previous studies: the $P$ wave velocity in the crust shallower than $10 \mathrm{~km}$ is based on a refraction experiment (Iwasaki et al 2004) and the velocity in the crust deeper than $10 \mathrm{~km}$ is based on a seismic tomography analysis (Katsumata et al 2006). The second one is the same velocity structure as used in the hypocenter determination. The major difference between the two structures is the presence or absence of

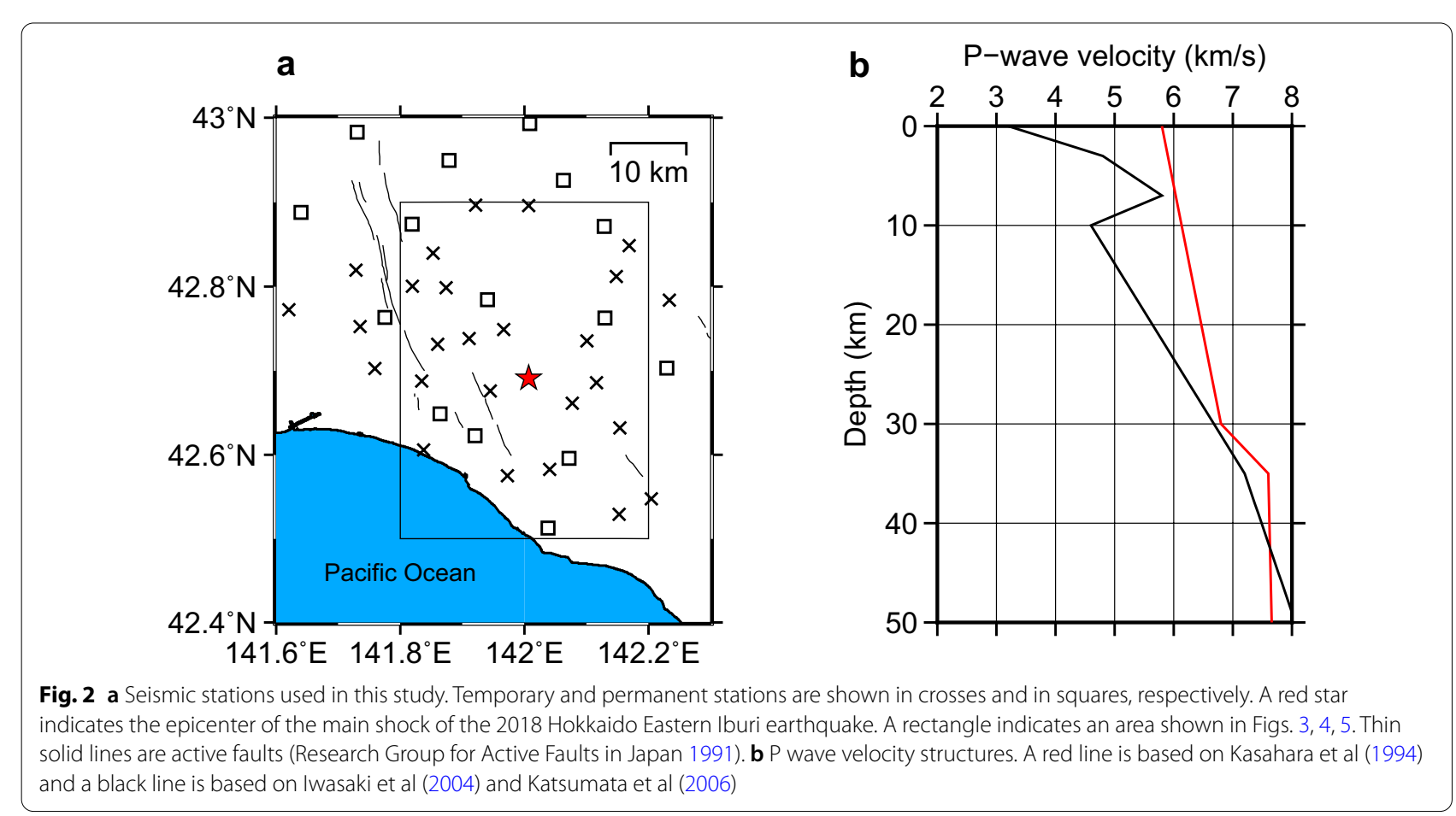



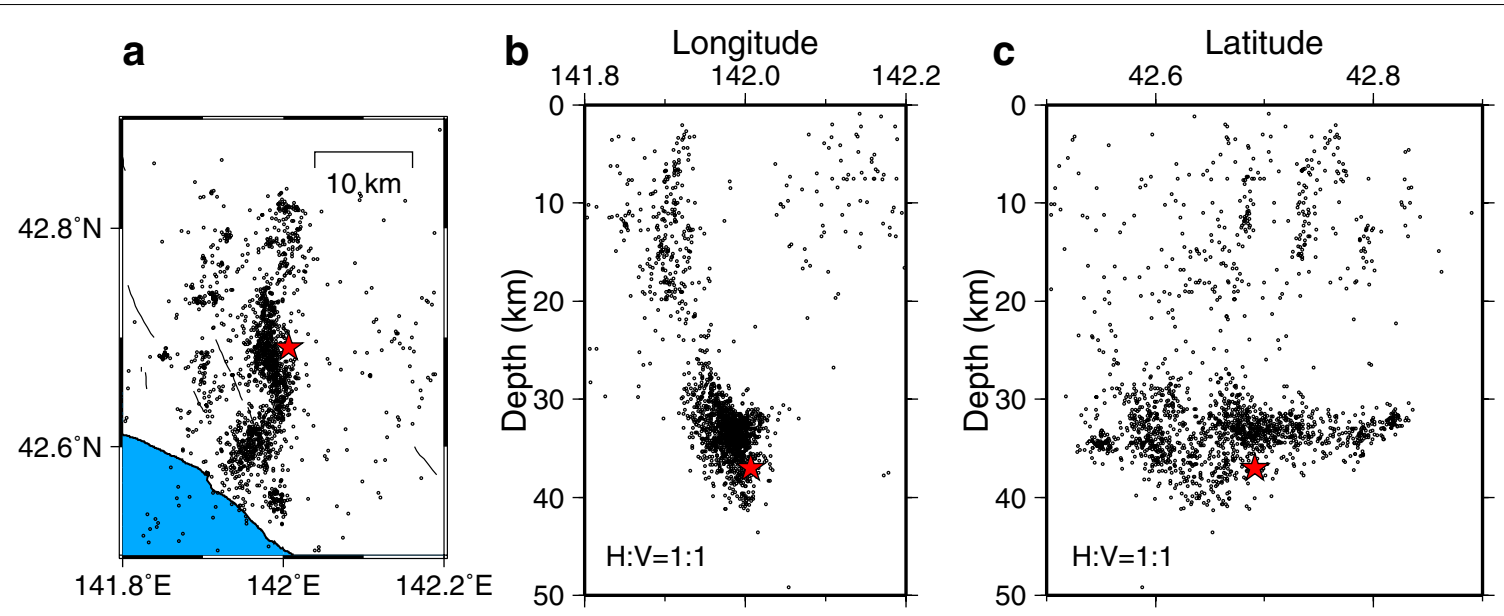

Fig. 3 Hypocenter distribution of aftershocks of the 2018 Hokkaido Eastern Iburi earthquake. a Epicenter distribution of aftershocks. A red star indicates the epicenter of the main shock. Thin solid lines are active faults (Research Group for Active Faults in Japan 1991). b Vertical cross section in East-West. A red star indicates the hypocenter of the main shock. $\mathbf{c}$ Vertical cross section in North-South. A red star indicates the hypocenter of the main shock

low-velocity sedimentary layers in the shallow part. No amplitude data were used.

There are several stress inversion methods to estimate the state of stress from focal mechanisms. Only four independent components are able to be obtained from the stress inversion method: the orientation (trend $t r$ and plunge $p l$ angle) of the axes of three principal stresses and the stress ratio. The trend $t r$ is an azimuthal angle: $t r=0^{\circ}$, $90^{\circ}, 180^{\circ}$, and $270^{\circ}$ indicate the north, the east, the south, and the west, respectively. The plunge is measured from the horizontal: $p l=0^{\circ}$ and $90^{\circ}$ indicate horizontal and vertical axes, respectively. The principal stresses are the maximum principal stress $\left(\sigma_{1}\right)$, the intermediate principal stress $\left(\sigma_{2}\right)$, and the minimum principal stress $\left(\sigma_{3}\right)$ and the stress ratio $R$ is defined as $R=\left(\sigma_{1}-\sigma_{2}\right) /\left(\sigma_{1}-\sigma_{3}\right)$, indicating the relative magnitude of the principal stresses and ranging from 0 to 1 . We determined the stress field with a stress inversion method developed by Hardebeck and Michael (2006) using focal mechanisms as input data. The method is performed by dividing the study area sufficiently fine in advance, putting a constraint that the stress changes smoothly between neighboring areas to avoid instability of the solution, and calculating the stress of all areas at once by using a least squares method. The uncertainty of the parameters is estimated using 2000 bootstrap resampling of all data (Hardebeck and Michael 2006). In this study, the two-dimensional nodes are placed in the aftershock area: the latitude ranges from 42.55 to $42.85^{\circ} \mathrm{N}$ and the grid spacing is $0.05^{\circ}$, the longitude is fixed at $142.0^{\circ} \mathrm{E}$ for all nodes, and the depth ranges from 8.2 to $45.1 \mathrm{~km}$ and the grid spacing is $4.1 \mathrm{~km}$. The focal mechanisms of aftershocks that occurred within $7 \mathrm{~km}$ from each node were used. The stress parameters were calculated at nodes with at least 8 focal mechanisms. We selected the damping parameter $e$ (Eq. (14) in Hardebeck and Michael 2006) based on the trade-off curve between the model length and the data variance. The corner of the trade-off curve was near $e \approx 1.2$, so we selected $e=1.2$ for all groups in this study.

\section{Results}

\section{Focal mechanisms}

We determined 894 focal mechanisms from 1785 aftershocks. Details of all focal mechanisms are given in the supplementary material (see Additional file 2). The number of polarity data ranged from 8 to 79 , and its average was about 30. There were 589 focal mechanisms with more than 20 first motion polarities. The nodal plane uncertainty ranged from $5^{\circ}$ to $70^{\circ}$, and the average uncertainty for the $1788(=894 \times 2)$ nodal planes of the 894 focal mechanisms was $29^{\circ}$. We evaluated the quality of the determined focal mechanisms as A, B, C, or D based on its estimation accuracy according to Hardebeck and Sherer (2002). Quality A and D solutions have the highest and lowest levels of quality, respectively. The number of focal mechanisms of Qualities A, B, C, and D were 234, 271,192 , and 197 , respectively. In this study, we use the 505 focal mechanisms of Qualities A and B in the following analyses (Fig. 4). The nodal plane uncertainty of these mechanisms ranges from $5^{\circ}$ to $41^{\circ}$, and the average for the $1010(=505 \times 2)$ nodal planes of the 505 focal mechanisms is $22^{\circ}$.

The averages of the trends of the $\mathrm{P}$ - and $\mathrm{T}$-axes are $\operatorname{tr}=78^{\circ} \pm 33^{\circ}$ and $352^{\circ} \pm 51^{\circ}$, respectively, for all 505 focal 


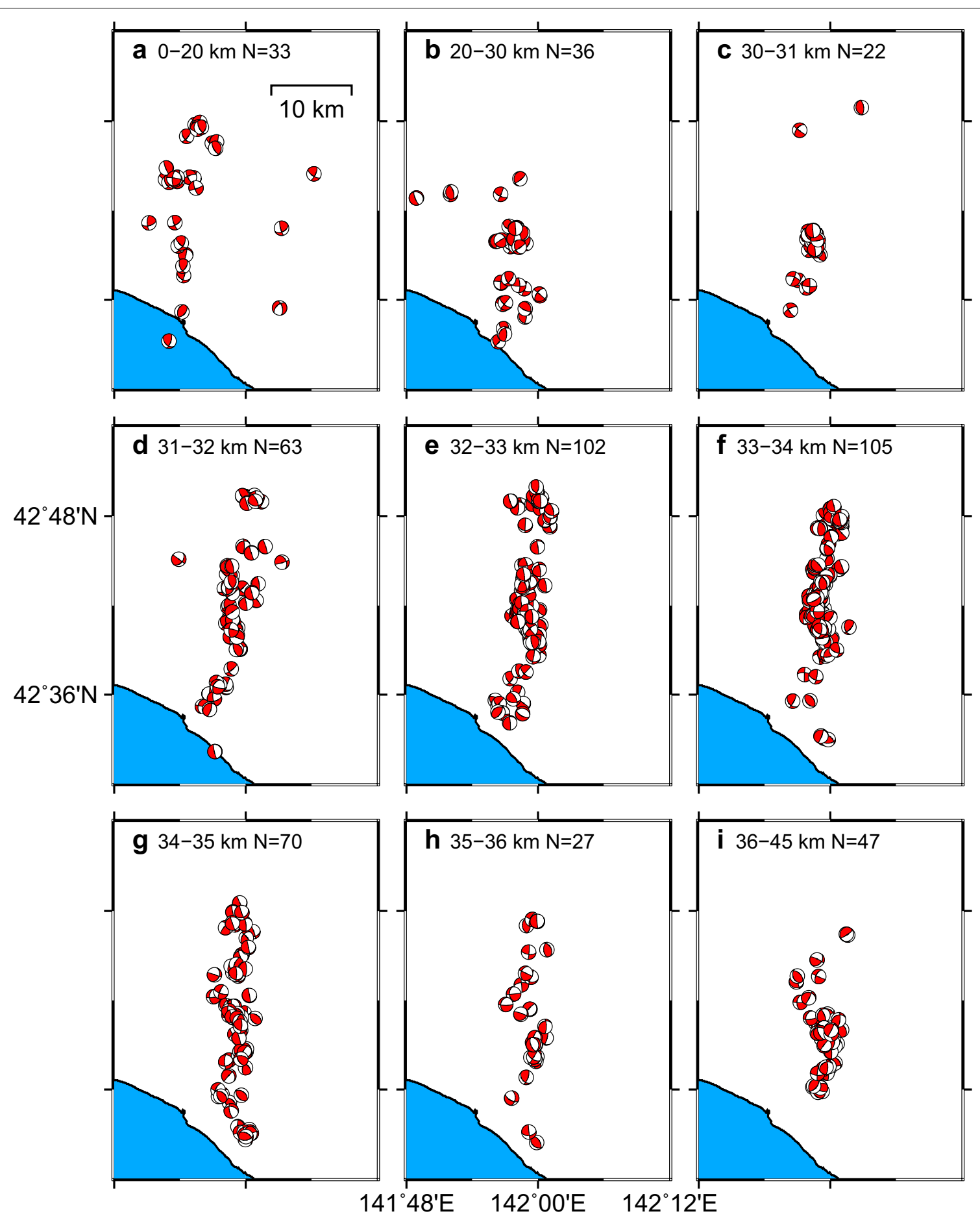

Fig. 4 Focal mechanism solutions with Quality A and B determined in this study. The depth of hypocenter is a $0-20 \mathrm{~km}, \mathbf{b} 20-30 \mathrm{~km}, \mathbf{c} 3 \mathbf{0}-31 \mathrm{~km}$, d $31-32 \mathrm{~km}$, e $32-33 \mathrm{~km}, \mathbf{f} 33-34 \mathrm{~km}, \mathbf{g} 34-35 \mathrm{~km}, \mathbf{h} 35-36 \mathrm{~km}$, and i 36-45 km. All diagrams are equal area projections on the lower hemisphere of the focal sphere. Colored areas show compressional quadrants

mechanisms of Quality A and B (Fig. 5). The averages of the plunges of the $\mathrm{P}$ - and $\mathrm{T}$-axes are $p l=25^{\circ} \pm 16^{\circ}$ and $44^{\circ} \pm 20^{\circ}$, respectively. The $\mathrm{T}$-axes have a larger plunge than the P-axes. These variations of the P- and T-axes come from the variations in the focal mechanisms. Triangle diagrams (Frohlich 2001) show the distribution of 

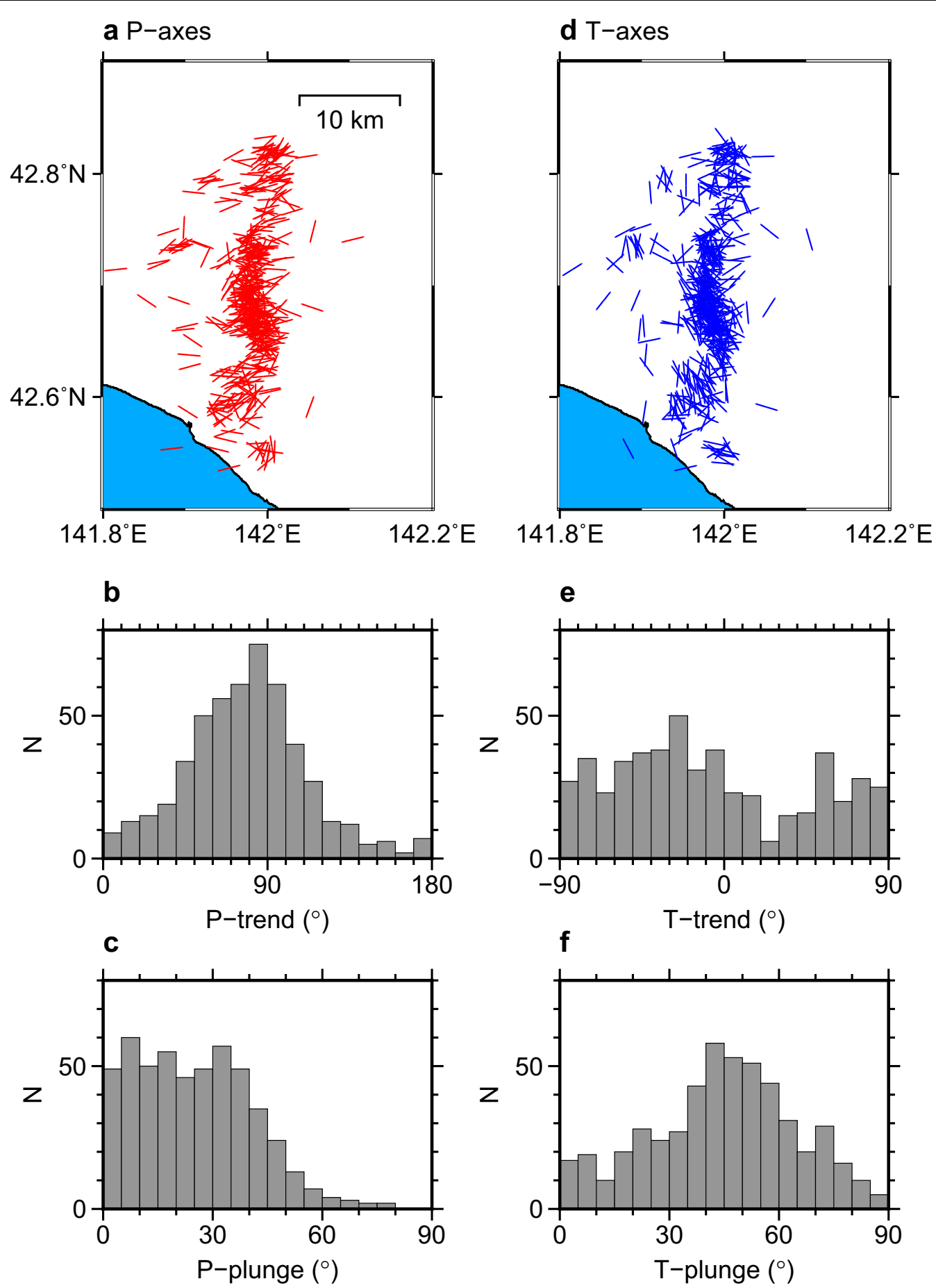

Fig. 5 Orientation of $\mathbf{a} \mathrm{P}$ - and $\mathbf{d}$ T-axes of the focal mechanisms with Quality $A$ and B shown in Fig. 4. Red lines in $\mathbf{a}$ and blue lines in $\mathbf{d}$ indicate the trend of the P-and T-axes, respectively. Histograms of the trend of $\mathbf{b} \mathrm{P}$ - and $\mathbf{e} \mathrm{T}$-axes. Histograms of the plunge of $\mathbf{c} \mathrm{P}$ - and $\mathbf{f} \mathrm{T}$-axes. The plunge of $0^{\circ}$ and $90^{\circ}$ indicate horizontal and vertical axes, respectively 


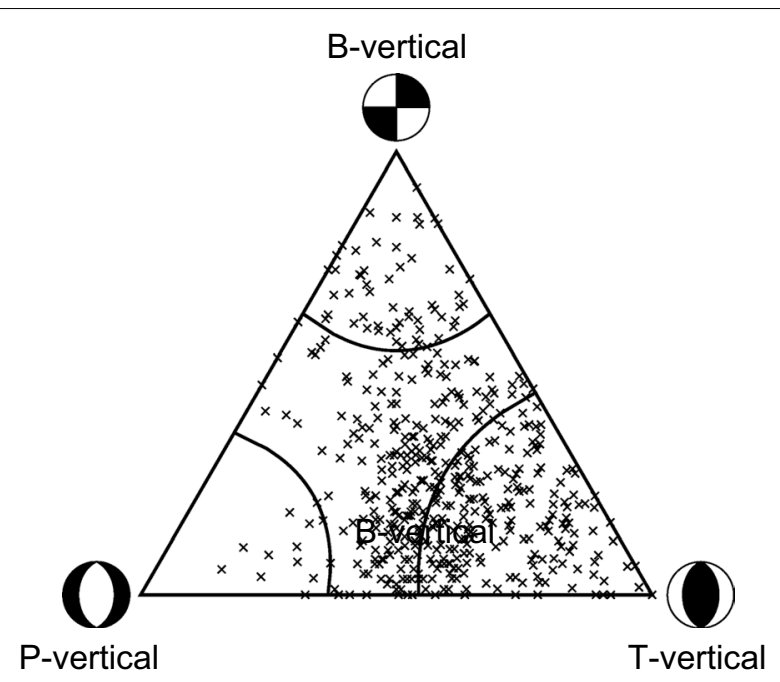

Fig. 6 Triangle diagram displaying the distribution of the focal mechanisms with Quality A and B shown in Fig. 4. Curved lines are boundaries with $\mathrm{T}, \mathrm{B}$, and $\mathrm{P}$ axes of $40^{\circ}, 30^{\circ}$, and $30^{\circ}$ from vertical, respectively (Frohlich 2001)
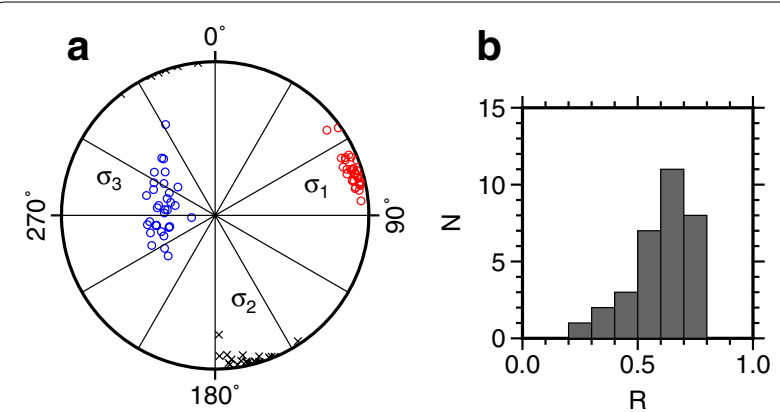

Fig. 7 Stress parameters at nodes shown in Fig. 8. a The orientation of principal stresses: red circles, crosses, and blue circles indicate $\sigma_{1}$, $\sigma_{2}$, and $\sigma_{3}$ at each node, respectively. $\mathbf{b}$ Histogram of the stress ratio $R=\left(\sigma_{1}-\sigma_{2}\right) /\left(\sigma_{1}-\sigma_{3}\right)$

focal mechanisms based on the plunge of the $\mathrm{P}-$, $\mathrm{T}-$, and B-axes (Fig. 6). In the study area, most focal mechanisms are classified into reverse fault, strike-slip fault, and other type's earthquakes, and few focal mechanisms are classified into normal fault earthquakes.

\section{Orientation of principal stresses}

We performed the stress inversion using the focal mechanisms in Fig. 4 and obtained the stress parameters at 32 nodes in the aftershock area of the 2018 Hokkaido Eastern Iburi earthquake. However, some focal mechanisms in Fig. 4 were located far from all nodes and they were not used for the inversion. The calculated values at each node are given in the supplementary material (see Additional file 3). The mean and the standard deviation of the parameters at the 32 nodes were calculated (Fig. 7 and Table 1). We found that the axis of $\sigma_{1}$ is oriented to ENE-WSW and the axis of $\sigma_{1}$ is close to be horizontal or tilting down to the eastward. The fault plane of the main shock dips approximately $70^{\circ}$ eastward (Kobayashi et al. 2019a,b; Guo et al. 2019). The $p l=19^{\circ}$ of $\sigma_{1}$ may promote the reverse faulting slip of the main shock. We also found that the axis of $\sigma_{3}$ is close to be vertical. Therefore, the results strongly suggest that the reverse fault type stress field is dominant, and the near-horizontal compressional stress is acting in the ENE-WSW direction in the aftershock area of the 2018 Hokkaido Eastern Iburi earthquake. According to JMA (2018a), the trend of P- and T-axes of the CMT solution of the main shock are $t r=67^{\circ}$ and $274^{\circ}$, respectively, and the plunge of $\mathrm{P}$ - and $\mathrm{T}$-axes are $p l=17^{\circ}$ and $71^{\circ}$, respectively. Therefore, the stress field obtained in this study is consistent with the CMT solution of the main shock. The vertical cross sections are shown in Fig. 8. No stress parameter was obtained in the aftershock area shallower than $20 \mathrm{~km}$ except for one node. There is no remarkable systematic spatial variation in trend and plunge of the $\sigma_{1}$ - and $\sigma_{3}$-axes in the aftershock area deeper than $20 \mathrm{~km}$. This observation suggests that at least the orientation of the principal stresses is uniform in the aftershock area.

\section{Depth dependence of the stress ratio $R$}

When the 32 nodes were averaged, the stress ratio $R$ was $0.61 \pm 0.13$ (Table 1). Ohtani and Imanishi (2019) conducted a stress inversion using 27 focal mechanisms in the aftershock area and obtained the stress ratio $\phi=1.0$ $R=0.57$. Since they did not describe the exact value of $\phi$ in the text, the approximate values were read from a histogram in Fig. 2b of Ohtani and Imanishi (2019). The value $\phi=0.57$, that is, $R=0.43$ is almost in the range of $1 \sigma(=0.13)$ and thus we cannot say statistically that the stress ratio $R=0.43$ obtained by Ohtani and Imanishi (2019) is different from $R=0.61$ obtained in this study. Consequently, from the point of view of the average of the entire aftershock area, there is no significant difference between the result of Ohtani and Imanishi (2019) and ours.

Table 1 Principal stresses averaged over the aftershock area

\begin{tabular}{llllll}
\hline $\boldsymbol{\sigma}_{\mathbf{1}}$ & $\boldsymbol{\sigma}_{\mathbf{1}}$ & $\boldsymbol{\sigma}_{\mathbf{2}}$ & $\boldsymbol{\sigma}_{\mathbf{2}}$ & $\boldsymbol{\sigma}_{\mathbf{3}}$ & $\boldsymbol{\sigma}_{\mathbf{3}}$ \\
\hline $\operatorname{tr}\left(^{\circ}\right)$ & $p /\left(^{\circ}\right)$ & $\operatorname{tr}\left(^{\circ}\right)$ & $p /\left(^{\circ}\right)$ & $\operatorname{tr}\left(^{\circ}\right)$ & $p /\left(^{\circ}\right)$ \\
$72 \pm 7$ & $19 \pm 4$ & $131 \pm 73$ & $10 \pm 9$ & $278 \pm 25$ & $0.61 \pm 0.13$ \\
\hline
\end{tabular}



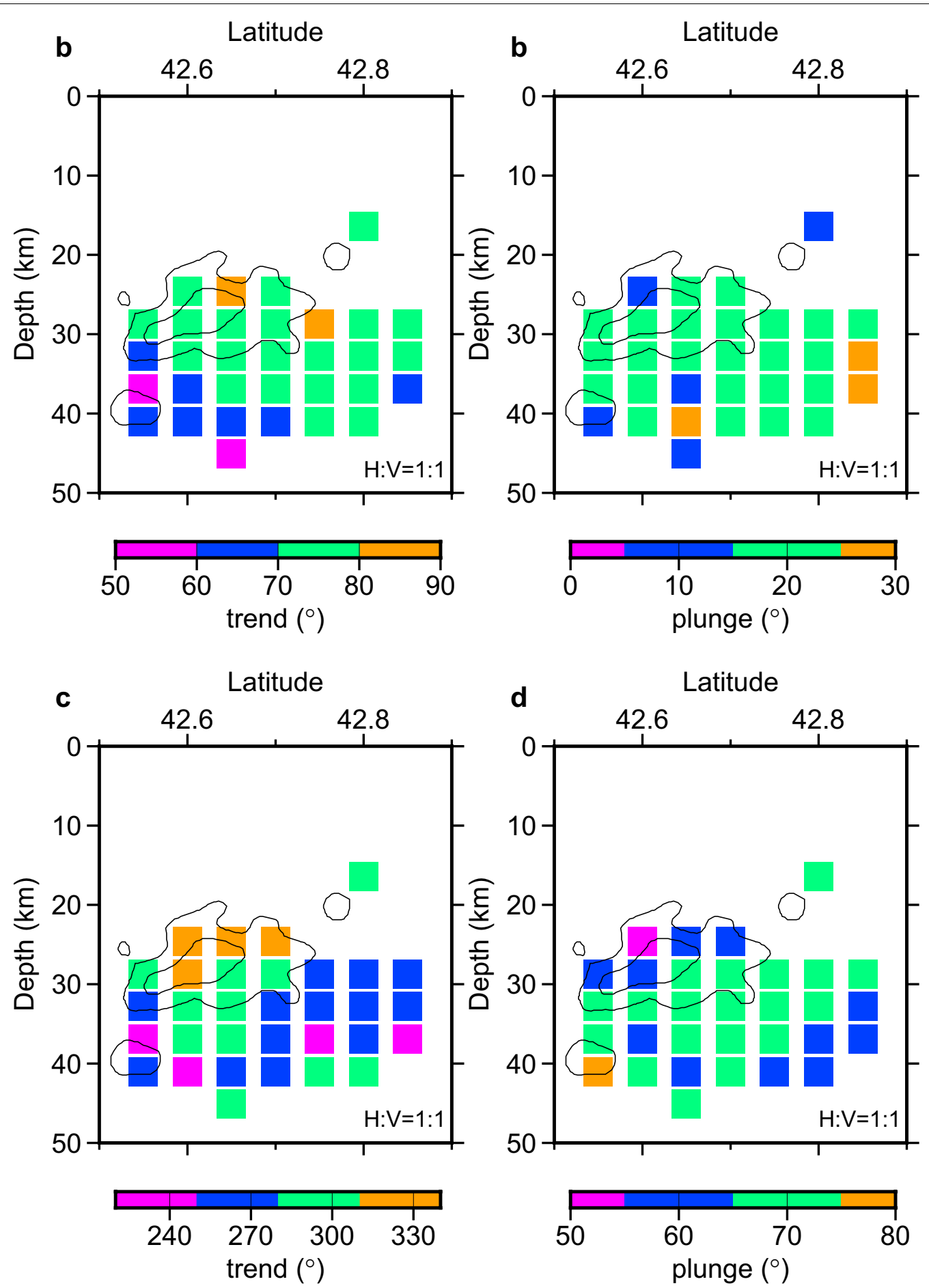

Fig. 8 Spatial pattern of the trend and the plunge. a The trend of $\sigma_{1}$-axis, $\mathbf{b}$ the plunge of $\sigma_{1}$-axis, $\mathbf{c}$ the trend of $\sigma_{3}$-axis, and $\mathbf{d}$ the plunge of $\sigma_{3}$-axis. The coseismic slip was indicated by contours with 0.6 and $1.2 \mathrm{~m}$ (Asano and Iwata 2019)

The estimated value of $R$ at each node has a very large error (see Additional file 3). The difference in the values between the nodes falls within the error range, and it cannot be said that there is a statistically significant difference. Therefore, the following judgment is reasonable: it is futile to discuss further the spatial pattern of stress 
ratios. Although we know that there is no statistical significance, we dare to propose a hypothesis that $R$ may have depth dependence in this study, as seen in the averaged values of $R$.

There seems to be depth dependence: $R$ decreases systematically from the shallow to the deep portions (Fig. 9). To express the depth dependency quantitatively, we estimated a best-fitted curve of $R$ as a function of the depth. The nodes in the depth direction are located from a depth of $16.4-45.1 \mathrm{~km}$ with an interval of $4.1 \mathrm{~km}$. We calculated

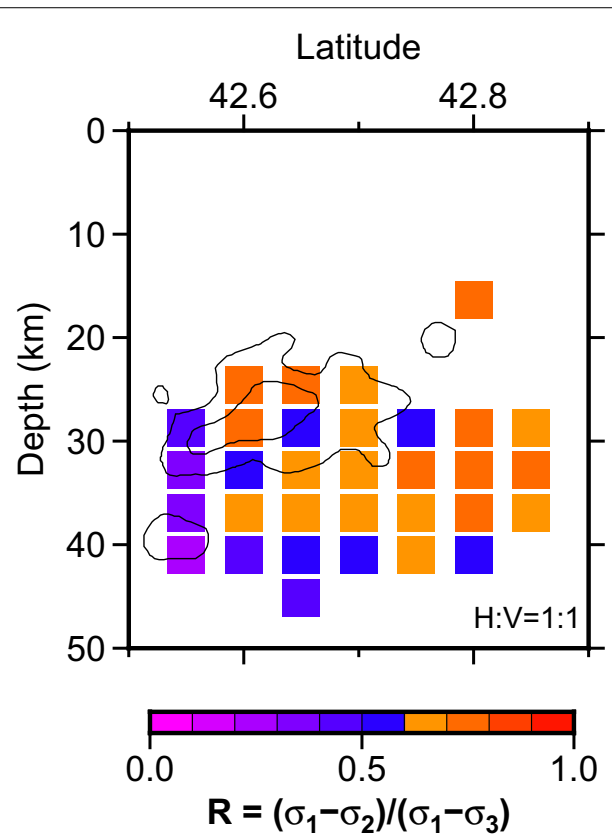

Fig. 9 Distribution of the stress ratio $R$ in vertical cross section. The coseismic slip was indicated by contours with 0.6 and $1.2 \mathrm{~m}$ (Asano and Iwata 2019) the average value of $R$ at each depth (Fig. 10a). By fitting the polynomials of 0 th to $3 \mathrm{rd}$ to the average value of $R$, AIC was calculated, and the optimal order of the polynomial was determined:

$$
R=\sum_{n=0}^{m} a_{n} z^{n}(m=0,1,2,3)
$$

where $R$ is the stress ratio averaged at each depth and $z$ is the depth in $\mathrm{km}$. The result of the polynomial fitting to $R$ was shown on Table 2. AIC is the smallest when $m=2$, therefore the depth dependence of $R$ is not linear but quadratic.

The maximum shear stress is defined as $\tau_{\max }=\left(\sigma_{1}-\sigma_{3}\right) / 2$. Based on the depth dependency of $R$, we estimated $\tau_{\max }$ as a function of depth with assumptions as follows: (1) $R$ is given by a quadratic polynomial of depth as described above, (2) the minimum principal stress $\sigma_{3}$ is equal to the lithostatic overburden pressure minus hydrostatic pressure, $\sigma_{3}(z)=16.7 z(\mathrm{MPa})$ at $z \mathrm{~km}$ depth (e.g. Aochi and Ulrich 2015; Ando and Kaneko 2018; Hisakawa et al 2020), and (3) $\sigma_{2} \approx \sigma_{3}$ (Hisakawa et al 2020) in this case we assumed $\sigma_{2}=1.01 \sigma_{3}$. As a result of a simple arithmetic calculation, $\tau_{\max }$ monotonically increases up to a depth of $32 \mathrm{~km}$, reaches a maximum

Table 2 Polynomial fitting to the stress ratio $R$

\begin{tabular}{lllllr}
\hline $\boldsymbol{m}$ & $\boldsymbol{a}_{\mathbf{0}}$ & $\boldsymbol{a}_{\mathbf{1}}$ & $\boldsymbol{a}_{\mathbf{2}}$ & $\boldsymbol{a}_{\mathbf{3}}$ & \multicolumn{1}{c}{ AIC } \\
\hline 0 & $6.00 \times 10^{-1}$ & & & & 2.613 \\
1 & $9.18 \times 10^{-1}$ & $-9.87 \times 10^{-3}$ & & -0.402 \\
2 & $5.12 \times 10^{-1}$ & $1.89 \times 10^{-2}$ & $-4.66 \times 10^{-4}$ & & -2.651 \\
3 & $7.93 \times 10^{-3}$ & $7.28 \times 10^{-2}$ & $-2.26 \times 10^{-3}$ & $1.88 \times 10^{-5}$ & 0.933 \\
\hline
\end{tabular}

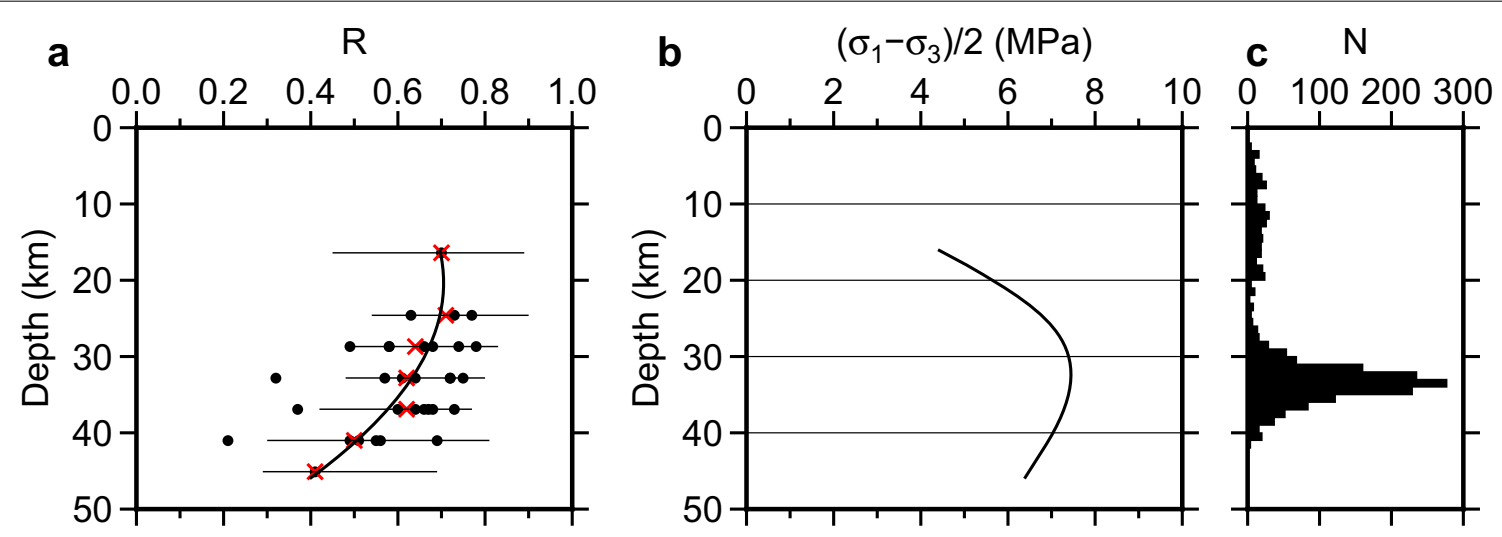

Fig. 10 Depth dependency of the stress ratio $R$. a Black dots are the $R$-value at each node and red crosses are the averaged values at each depth. Horizontal thin lines indicate the estimation error. A curved line is the best fitted line to the red crosses. $\mathbf{b}$ The maximum shear stress $\tau_{\max }=\left(\sigma_{1}-\sigma_{3}\right) / 2$ as a function of depth. $\mathbf{c}$ Histogram of the depth of aftershocks shown in Fig. 3 
value, and then decreases below $32 \mathrm{~km}$ (Fig. 10b). Interestingly, the aftershock activity concentrates around the depth of $32 \mathrm{~km}$ (Fig. 10c). Note that the important point is not the absolute value of $\tau_{\max }$, but the change pattern of increase/maximum value/decrease. The absolute value depends on how you suppose the relationship between $\sigma_{2}$ and $\sigma_{3}$. For example, if you assumed $\sigma_{2}=1.1 \sigma_{3}, \tau_{\max }$ is 10 times larger.

\section{Discussion \\ Reverse-faulting stress field in the western boundary of the $\mathrm{HCZ}$}

In this study, the state of stress was revealed in the aftershock area of the 2018 Hokkaido Eastern Iburi earthquake $\left(M_{\text {JMA }}=6.7\right)$ which is in the western boundary of the Hidaka Collision Zone (HCZ). The state of stress revealed by a stress inversion analysis of the aftershocks showed that the dominant stress field is the reverse fault type, the $\sigma_{1}$-axis is in the direction of ENE-WSW, i.e., $t r=72^{\circ}$, and the $\sigma_{1}$-axis is close to be horizontal. The direction of ENE-WSW is clearly different from the convergence direction of the PA plate. Therefore, a model that the compressional stress field due to the collision extends to the western boundary of the $\mathrm{HCZ}$ is strongly supported by not only the CMT solution of the 2018 main shock but also the focal mechanisms of its aftershocks.

Terakawa and Matsu'ura (2010) insisted that the stress field of reverse faulting type is dominant in the aftershock area of the 2018 Hokkaido Eastern Iburi earthquake: the axis of $\sigma_{1}$ is close to be horizontal with almost EW direction and the axis of $\sigma_{3}$ is near-vertical. The results obtained in this study are consistent with those obtained by Terakawa and Matsu'ura (2010). Kita et al (2012). applied a stress inversion analysis to focal mechanisms of small earthquakes occurred in and around an area $100 \mathrm{~km}$ east of the 2018 main shock. As a result, they found that the trend and the plunge of $\sigma_{1}$-axis are $224^{\circ}$ and $20^{\circ}$, respectively. The trend of $\sigma_{1}$-axis obtained by Kita et al (2012) is different from that obtained in this study. This difference might suggest the stress field is not uniform in the HCZ.

\section{A possible cause of the aftershock concentration in the deeper zone than $30 \mathrm{~km}$}

Many authors pointed out that aftershocks concentrate not within the large coseismic slip area but in its surrounding area (e.g. Mendoza and Hartzell 1988; Beroza and Zoback 1993; Das and Henry 2003; Hsu et al. 2006; Woessner et al. 2006; Perfettini et al. 2010; Asano et al. 2011; Kato and Igarashi 2012). These observations strongly suggest that aftershocks are induced by the local accumulation of the shear stress due to the rupture of main shock.

The aftershock activity of the 2018 Hokkaido Eastern Iburi earthquake concentrates between 30 and $40 \mathrm{~km}$ in depth. The depth of D90 is approximately $25 \mathrm{~km}$ in this area (Omuralieva et al 2012). The depth of D90 is defined as the depth above which $90 \%$ of the earthquakes occur. The aftershock concentration zone is much deeper than the depth of D90. In this study we suggested that the stress ratio $R$ decreases as a quadratic polynomial of depth from 16 to $45 \mathrm{~km}$ and this change is due to the maximum shear stress $\tau_{\max }$ that increases from 16 to $32 \mathrm{~km}$ and decreases from 32 to $45 \mathrm{~km}$. The aftershock activity has concentrated in the zone that the $\tau_{\max }$ becomes the maximum. Some authors have reported the coseismic slip distribution and showed that the seismic fault ruptured by the main shock did not expand deeper than $30 \mathrm{~km}$ (Kobayashi et al. 2019a,b; Asano and Iwata 2019). Asano and Iwata (2019) analyzed the strongmotion data by using a kinematic waveform inversion method and found that the peak slip of $1.7 \mathrm{~m}$ was located at a depth of about $26 \mathrm{~km}$, southwest of the epicenter.

A key to explain these observations is the brittle-ductile transition zone. The depth to the Moho is approximately $30 \mathrm{~km}$ in the aftershock area (Yoshii 1972; Matsubara et al 2017) and the temperature at the Moho is estimated to be $400-600{ }^{\circ} \mathrm{C}$ (Fujiwara 1984; Nishida and Hashimoto 2007). The deeper part of the aftershock area than $30 \mathrm{~km}$ is likely to be the brittle-ductile transition zone. Although a long-term stress of thousands of years does not accumulate in the brittle-ductile transition zone, a short-term stress of several years accumulates. Therefore, we suggest that the rupture of the main shock was limited shallower than $30 \mathrm{~km}$, due to this rupture, a transient shear stress was loaded in the mantle deeper than $30 \mathrm{~km}$, and the aftershock activity was induced there. Hisakawa et al (2020) conducted a dynamic rupture simulation of the 2018 Hokkaido Eastern Iburi earthquake and showed that the shear stress rise of $10-15 \mathrm{MPa}$ is possible theoretically near the boundary on the deep side of the large cosismic slip area.

\section{Conclusions}

We deployed temporary seismic stations immediately after the main shock of the 2018 Hokkaido Eastern Iburi earthquake $\left(M_{\mathrm{IMA}}=6.7\right)$. The dense seismic stations enabled us to determine focal mechanism solutions accurately by using the first motion polarity of $\mathrm{P}$ wave. A stress inversion method was applied to the focal mechanism solutions to investigate the state of stress in the aftershock area. At deeper than $20 \mathrm{~km}$, the orientation of $\sigma_{1^{-}}$and $\sigma_{3}$-axes seemed to be uniform. Moreover, what is interesting is the depth dependence of the stress ratio $R$. Although the statistical significance is 
very poor, we dare to present a model that the $R$ value is a quadratic polynomial of depth, indicating the change in shear stress that has a maximum around $32 \mathrm{~km}$ in depth. Although the coseismic slip seems to best explain the depth dependence of the shear stress, this model is a hypothesis to examine in future works.

\section{Supplementary Information}

The online version contains supplementary material available at https://doi. org/10.1186/s40623-020-01323-x.

Additional file 1. Temporary seismic stations.

Additional file 2. Focal mechanism solutions determined in this study.

Additional file 3. Stress parameters at each node.

\section{Acknowledgements}

We thank Takuya Nishimura, Andrew Michael, and an anonymous reviewer for valuable comments. We thank Toshiko Terakawa for valuable discussions. We used waveform data from seismic stations maintained by JMA, and we also used waveform data from High-Sensitivity Seismograph Network of Japan (Hi-net) maintained by NIED. We used observation equipment at some seismic stations supported by the Earthquake Research Institute Joint Usage/Research Program 2016-F2-02, 2017-F2-02, 2018-F2-02, 2019-F2-02, and 2020F2-02. GMT-SYSTEM (Wessel and Smith 1991) was used for mapping data.

A list of individual members of the Group for the Aftershock Observations of the 2018 Hokkaido Eastern Iburi Earthquake follows: Yuki Susukida'1, ${ }^{11}$, Kei Katsumata', Masayoshi Ichiyanagi', Mako Ohzono', Hiroshi Aoyama', Ryo Tanaka', Masamitsu Takada', Teruhiro Yamaguchi', Kazumi Okada', Hiroaki Takahashi', Shin'ichi Sakai², Koji Miyakawa², Shin'ichi Tanaka², Miwako Ando², Satoshi Matsumoto ${ }^{3}$, Tomomi Okada ${ }^{4}$, Toru Matsuzawa ${ }^{4}$, Naoki Uchida ${ }^{4}$, Ryosuke Azuma ${ }^{4}$, Ryota Takagi4, Keisuke Yoshida ${ }^{4}$, Takashi Nakayama ${ }^{4}$, Satoshi Hirahara ${ }^{4}$, Toshiko Terakawa ${ }^{5}$, Yoshiko Yamanaka ${ }^{5}$, Yuta Maeda ${ }^{5}$, Shinichiro Horikawa ${ }^{5}$, Hiroki Miyamachi ${ }^{6}$, Shuichiro Hirano ${ }^{6}$, Hiroshi Yakiwara ${ }^{6}$, Masahiro Kosuga ${ }^{7}$, Takuto Maeda ${ }^{7}$, Hiroshi Katao ${ }^{8}$, Yoshihisa lio $^{8}$, Airi Nagaoka ${ }^{8}$, Noriko Tsumura ${ }^{9}$, Masahiro Shimazaki ${ }^{9}$, Tomotake Ueno ${ }^{10}$, and Youichi Asano ${ }^{10}$, where ${ }^{1}$ Hokkaido University, ${ }^{2}$ University of Tokyo, ${ }^{3}$ Kyushu University, ${ }^{4}$ Tohoku University, ${ }^{5}$ Nagoya University, ${ }^{6}$ Kagoshima University, ${ }^{7}$ Hirosaki University, ${ }^{8}$ Kyoto University, ${ }^{9}$ Chiba University, ${ }^{10}$ National Research Institute for Earth Science and Disaster Resilience and " ${ }^{1}$ KOZO KEIKAKU ENGINEERING Inc., Tokyo, Japan.

\section{Authors' contributions}

YS determined the focal mechanisms and conducted the stress inversion. KK was a major contributor in writing the manuscript. Ml read all arrival times of $P$ and $S$ waves and the first motion polarity of $P$ wave. MO, HA, RT, MT, TY, KO, and $\mathrm{HT}$ are the technical staff members who maintain the seismic stations of Hokkaido University and the temporary seismic stations. SS, SM, TO, TM, HM, SH, YY, SH, MK, HK, YI, AN, NT, TU, and members of the Group for the Aftershock Observations are important persons to maintain the temporary seismic stations. All authors read and approved the final manuscript.

\section{Funding}

This study was partly supported by the Ministry of Education, Culture, Sports, Science and Technology (MEXT) of Japan, under its "The Second Earthquake and Volcano Hazards Observation and Research Program (Earthquake and Volcano Hazard Reduction Research)". This study was also partly supported by MEXT KAKENHI grant $18 K 19952$.

\section{Availability of data and materials}

The datasets used and/or analyzed during the current study are available from the corresponding author on reasonable request.

\section{Competing interests}

The authors declare that they have no competing interests.

\section{Author details}

${ }^{1}$ Faculty of Science, Institute of Seismology and Volcanology, Hokkaido University, Sapporo, Japan. ${ }^{2}$ Earthquake Research Institute, University of Tokyo, Tokyo, Japan. ${ }^{3}$ Institute of Seismology and Volcanology, Kyushu University, Fukuoka, Japan. ${ }^{4}$ Research Center for Prediction of Earthquakes and Volcanic Eruptions, Tohoku University, Sendai, Japan. ${ }^{5}$ Graduate School of Science and Engineering, Kagoshima University, Kagoshima, Japan. ${ }^{6}$ Nansei-Toko Observatory for Earthquakes and Volcanoes, Research and Education Center for Natural Hazards, Kagoshima University, Kagoshima, Japan. ${ }^{7}$ Earthquake and Volcano Research Center, Graduate School of Environmental Studies, Nagoya University, Nagoya, Japan. ${ }^{8}$ Earthquake and Volcano Observatory, Hirosaki University, Hirosaki, Japan. ${ }^{9}$ Disaster Prevention Research Institute, Kyoto University, Kyoto, Japan. ${ }^{10}$ Department of Earth Science, Faculty of Science, Chiba University, Chiba, Japan. ${ }^{11}$ National Research Institute for Earth Science and Disaster Resilience, Tsukuba, Japan. ${ }^{12}$ Present Address: Kozo Keikaku Engineering Inc., Tokyo, Japan.

Received: 8 July 2020 Accepted: 25 November 2020 Published online: 01 January 2021

\section{References}

Ando R, Kaneko Y (2018) Dynamic rupture simulation reproduces spontaneous multifault rupture and arrest during the $2016 M_{w} 7.9$ Kaikoura earthquake. Geophys Res Lett 45:12875-12883. https://doi.org/10.1029/2018g 1080550

Aochi H, Ulrich T (2015) A probable earthquake scenario near Istanbul determined from dynamic simulations. Bull Seismol Soc Am 105(3):1468-1475. https://doi.org/10.1785/0120140283

Arita K, Ganzawa Y, Itaya T (2001) Tectonics and uplift process of the Hidaka Mountains, Hokkaido, Japan inferred from thermochronology [in Japanese]. Bull Earthq Res Inst Univ Tokyo 76:93-104

Asano K, Iwata T (2019) Source rupture process of the 2018 Hokkaido Eastern Iburi earthquake deduced from strong-motion data considering seismic wave propagation in three-dimensional velocity structure. Earth Planets Space 71:101. https://doi.org/10.1186/s40623-019-1080-0

Asano Y, Saito T, Ito Y, Shiomi K, Hirose H, Matsumoto T, Aoi S, Hori S, Sekiguchi $S$ (2011) Spatial distribution and focal mechanisms of aftershocks of the 2011 off the Pacific coast of Tohoku earthquake. Earth Planets Space 63:669-673. https://doi.org/10.5047/eps.2011.06.016

Beroza GC, Zoback MD (1993) Mechanism diversity of Loma Prieta aftershocks and the mechanics of mainshock-aftershock interaction. Science 259:210-213. https://doi.org/10.1126/science.259.5092.210

Bird P (2003) An updated digital model of plate boundaries. Geochem Geophys Geosyst 4(3):1027. https://doi.org/10.1029/2001GC000252

Das S, Henry C (2003) Spatial relation between main earthquake slip and its aftershock distribution. Rev Geophys 41 (3):1013. https://doi. org/10.1029/2002RG000119

DeMets C (1992) Oblique convergence and deformation along the Kuril and Japan Trenches. J Geophys Res 97:17615-17625. https://doi. org/10.1029/92JB01306

DeMets C, Gordon RG, Argus DF, Stein S (1994) Effect of recent revisions to the geomagnetic reversal time scale on estimates of current plate motions. Geophys Res Lett 21:2191-2194. https://doi.org/10.1029/94GL02118

Frohlich C (2001) Display and quantitative assessment of distributions of earthquake focal mechanisms. Geophys J Int 144:300-308. https://doi. org/10.1046/j.1365-246x.2001.00341.x

Fujiwara N (1984) Temperature distribution at the Moho, in and around the Japanese Islands [in Japanese]. J Geothermal Res Society Jpn 6:183-202. https://doi.org/10.11367/grsj1979.6.183

Guo Z et al (2019) Fault Slip Model of the 2018 Mw 6.6 Hokkaido Eastern Iburi, Japan, Earthquake Estimated from Satellite Radar and GPS Measurements. Remote Sensing 11:1667. https://doi.org/10.3390/rs11141667

Hardebeck JL, Michael AJ (2006) Damped regional-scale stress inversions: methodology and examples for southern California and the Coalinga aftershock sequence. J Geophys Res 111:B11310. https://doi. org/10.1029/2005JB004144

Hardebeck JL, Shearer PM (2002) A new method for determining first-motion focal mechanisms. Bull Seism Soc Am 92:2264-2276. https://doi. org/10.1785/0120010200 
Hashimoto C, Noda A, Sagiya T et al (2009) Interplate seismogenic zones along the Kuril-Japan trench inferred from GPS data inversion. Nat Geosci 2:141-144. https://doi.org/10.1038/ngeo421

Hirata N, Matsu' ura M (1987) Maximum-likelihood estimation of hypocenter with origin time eliminated using nonlinear inversion technique. Phys Earth Planet Inter 47:50-61. https://doi.org/10.1016/0031-9201(87)90066 $-5$

Hisakawa T, Ando R, Yano TE et al (2020) Dynamic rupture simulation of 2018, Hokkaido Eastern Iburi earthquake: role of non-planar geometry. Earth Planets Space 72:36. https://doi.org/10.1186/s40623-020-01160-y

Hsu YJ et al (2006) Frictional afterslip following the 2005 Nias-Simeulue earthquake, Sumatra. Science 312:1921-1926. https://doi.org/10.1126/ science. 1126960

Hua YY, Zhao DP, Xu YX, Wang ZW (2019) Arc-arc collision caused the 2018 Eastern Iburi earthquake (M 6.7) in Hokkaido, Japan. Sci Rep 9:13914. https://doi. org/10.1038/s41598-019-50305-x

Ito Tet al (1999) Delamination wedge structure beneath the Hidaka collision zone [in Japanese]. Chikyu Mon 21(3):130-136

Iwasaki T et al (2004) Upper and middle crustal deformation of an arc-arc collision across Hokkaido, Japan, inferred from seismic refraction/wide-angle reflection experiments. Tectonophysics 388:59-73. https://doi.org/10.1016/j.tecto 2004.03.025

JMA (2018a) The CMT solutions. https://www.data.jma.go.jp/svd/eqev/data/ mech/cmt/fig/cmt20180906030759.html. Accessed 16 June 2020

JMA (2018b) Focal mechanism solutions by using first motion polarities. https:// www.data.jma.go.jp/svd/eqev/data/mech/ini/fig/mc20180906030759.html. Accessed 16 June 2020.

Kasahara M, Kodaira S, Motoya Y (1994) Aftershock distribution of the 1993 Kushiro-oki earthquake and the seismicity in and around Hokkaido before the main shock. In: Research report on the damages from the 1993 Kushiro-oki earthquake, pp 27-34. Supported by the Japanese Ministry of Education, Science, Sport and Culture (Grant No. 04306025)

Kato A, Igarashi T (2012) Regional extent of the large coseismic slip zone of the 2011 Mw 9.0 Tohoku-Oki earthquake delineated by on-fault aftershocks. Geophys Res Lett 39:L15301. https://doi.org/10.1029/2012GL052220

Katsumata Ket al (2002) Distribution of hypocenters and focal mechanisms in and around the Hidaka arc-arc collision zone revealed by a dense temporary seismic network. Bull Earthq Res Inst Univ Tokyo 77:199-223

Katsumata K, Wada N, Kasahara M (2003) Newly imaged shape of the deep seismic zone within the subducting Pacific plate beneath the Hokkaido corner Japan-Kurile arc-arc junction. J Geophys Res 108(B12):2565. https:// doi.org/10.1029/2002JB002175

Katsumata K, Wada N, Kasahara M (2006) Three-dimensional P and S wave velocity structures beneath the Hokkaido corner, Japan-Kurile arc-arc junction. Earth Planets Space 58:e37-e40. https://doi.org/10.1186/BF03352595

Katsumata K, Ichiyanagi M, Ohzono M et al (2019) The 2018 Hokkaido Eastern Iburi earthquake (MJMA =6.7) was triggered by a strike-slip faulting in a stepover segment: insights from the aftershock distribution and the focal mechanism solution of the main shock. Earth Planets Space 71:53. https:// doi.org/10.1186/s40623-019-1032-8

Kimura G (1981) Tectonic evolution and stress field in the southwestern margin of the Kurile Arc. J Geol Soc Jpn 87:757-768. https://doi.org/10.5575/geoso c.87.757

Kimura G (1986) Oblique subduction and collision: forearc tectonics of the Kurile arc. Geology 14:404-407. https://doi.org/10.1130/00917613(1986)14\%3c404:OSACFT\%3e2.0.CO;2

Kimura G (1996) Collision orogeny at arc-arc junctions in the Japanese Islands. Island Arc 5:262-275. https://doi.org/10.1111/j.1440-1738.1996.tb00031.x

Kita S, Hasegawa A, Nakajima J, Okada T, Matsuzawa T, Katsumata K (2012) Highresolution seismic velocity structure beneath the Hokkaido corner, northern Japan: arc-arc collision and origins of the 1970 M 6.7 Hidaka and 1982 M 7.1 Urakawa-oki earthquakes. J Geophys Res 117:B12301. https://doi. org/10.1029/2012JB009356.a

Kobayashi T, Hayashi K, Yarai H (2019a) Geodetically estimated location and geometry of the fault plane involved in the 2018 Hokkaido Eastern Iburi earthquake. Earth Planets Space 71:62. https://doi.org/10.1186/s4062 3-019-1042-6

Kobayashi H, Koketsu K, Miyake H (2019b) Rupture process of the 2018 Hokkaido Eastern Iburi earthquake derived from strong motion and geodetic data. Earth Planets Space 71:63. https://doi.org/10.1186/s40623-019-1041-7
Matsubara M, Sato H, Ishiyama T, Horne AV (2017) Configuration of the Moho discontinuity beneath the Japanese Islands derived from three-dimensional seismic tomography. Tectonophysics 710-711:97-107. https://doi. org/10.1016/j.tecto.2016.11.025

Mendoza C, Hartzell SH (1988) Aftershock patterns and main shock faulting. Bull Seismol Soc Am 78(4):1438-1449

Moriya T (1972) Aftershock activity of the Hidaka Mountains earthquake of January 21, 1970 [in Japanese]. J Seismol Soc Jpn 24:287-297. https://doi. org/10.4294/zisin1948.24.4_287

Moriya T (1986) Collision of forearcs and the overlapped deep seismic zone in the transitional zone between the northern Honshu and Kurile arcs. J Phys Earth 34:S175-S192. https://doi.org/10.4294/jpe1952.34.Supplement_S175

Moriya T (1999) Seismicity associated with the triple collision structure in the southern part of the Hidaka Mountain Range, Hokkaido, Japan (in Japanese). Chikyu Mon Extra 27:206-210

Moriya T, Miyamachi H, Katoh S (1983) Spatial distribution and mechanism solutions for foreshocks, mainshock and aftershocks of the Urakawa-oki Earthquake of March 21, 1982 (in Japanese). Geophys Bull Hokkaido Univ 42:191-213. https://doi.org/10.14943/gbhu.42.191

Moriya et al (1998) Collision structure in the upper crust beneath the southwestern foot of the Hidaka Mountains, Hokkaido, Japan as derived from explosion seismic observations. Tectonophysics 290:181-196. https://doi. org/10.1016/S0040-1951(98)00011-0

Motoya Y, Kitagamae M (1971) Report on the earthquake of southern part of Hokkaido on January 21, 1970 (in Japanese). Geophys bull Hokkaido Univ 25:141-153. https://doi.org/10.14943/gbhu.25.141

Murai $Y$ et al (2003) Delamination structure imaged in the source area of the 1982 Urakawa-oki earthquake. Geophys Res Lett 30:1490. https://doi. org/10.1029/2002GL016459

NIED (2018a) Focal mechanisms automatically determined by the AQUA system. http://www.hinet.bosai.go.jp/AQUA/aqua_catalogue. php?y $=2018 \&$ m =09\&LANG=en. Accessed 14 Apr 2020

NIED (2018b) Recent large earthquakes. Tsukuba http://www.hinet.bosai.go.jp/ backnumber/?LANG=en\&y=2018\&m=09. Accessed 14 Apr 2020

Nishida Y, Hashimoto T (2007) Geothermal structure of the crust and the upper mantle in Hokkaido, Japan: a review [in Japanese]. Geophys Bull Hokkaido Univ 70:1-12. https://doi.org/10.14943/gbhu.70.1

Ohtani M, Imanishi K (2019) Seismic potential around the 2018 Hokkaido Eastern Iburi earthquake assessed considering the viscoelastic relaxation. Earth Planets Space 71:57. https://doi.org/10.1186/s40623-019-1036-4

Omuralieva AM, Hasegawa A, Matsuzawa T, Nakajima J, Okada T (2012) Lateral variation of the cutoff depth of shallow earthquakes beneath the Japan Islands and its implications for seismogenesis. Tectonophysics 518-521:93105. https://doi.org/10.1016/j.tecto.2011.11.013

Ozel O et al (1996) Crustal structure in the central Hokkaido, Japan, from a seismic refraction experiment. J Fac Sci 10:31-52. http://hdl.handle.net/2115/8808.

Perfettini Het al (2010) Seismic and aseismic slip on the central Peru megathrust. Nature 465:78-81. https://doi.org/10.1038/nature09062

Research Group for Active Faults in Japan (1991) Active faults in Japan: sheet maps and inventories. University of Tokyo Press, Tokyo

Seno T (1985) Northern Honshu microplate hypothesis and tectonics in the surrounding region: when did the plate boundary jump from central Hokkaido to the eastern margin of the Japan Sea? J Geodetic Soc Jpn 31:106-123. https://doi.org/10.11366/sokuchi1954.31.106

Shiina T, Takahashi H, Okada T, Matsuzawa T (2018) Implications of seismic velocity structure at the junction of Kuril-northeastern Japan arcs on active shallow seismicity and deep low-frequency earthquakes. J Geophys Res Solid Earth 123:8732-8747. https://doi.org/10.1029/2018JB015467

Takahashi H et al (1999) Velocity field of around the Sea of Okhotsk and Sea of Japan regions determined from a new continuous GPS network data. Geophys Res Lett 26:2533-2536. https://doi.org/10.1029/1999GL900565

Terakawa T, Matsu'ura M (2010) The 3-D tectonic stress fields in and around Japan inverted from centroid moment tensor data of seismic events. Tectonics 29:TC6008. https://doi.org/10.1029/2009TC002626

Tsumura N et al (1999) Delamination-wedge structure beneath the Hidaka Collision Zone, Central Hokkaido, Japan inferred from seismic reflection profiling. Geophys Res Lett 26:1057-1060. https://doi.org/10.1029/1999GL900192

Watanabe H (1971) Determination of earthquake magnitude at regional distance in and near Japan [in Japanese]. J Seismol Soc Jpn 32:281-296. https://doi. org/10.4294/zisin1948.24.3_189 
Wessel P, Smith WHF (1991) Free software helps map and display data. Eos Trans AGU 72:445-446

Woessner J, Schorlemmer D, Wiemer S, Mai PM (2006) Spatial correlation of aftershock locations and on-fault main shock properties. J Geophys Res 111:B08301. https://doi.org/10.1029/2005JB003961

Yoshii T (1972) Terrestrial heat flow and features of the upper mantle beneath the Pacific and the Sea of Japan. J Phys Earth 20:271-285. https://doi. org/10.4294/jpe1952.20.271

\section{Publisher's Note}

Springer Nature remains neutral with regard to jurisdictional claims in published maps and institutional affiliations.
Submit your manuscript to a SpringerOpen ${ }^{\circ}$ journal and benefit from:

- Convenient online submission

- Rigorous peer review

- Open access: articles freely available online

- High visibility within the field

- Retaining the copyright to your article

Submit your next manuscript at $\boldsymbol{\nabla}$ springeropen.com 